$\mathbb{T}$ periodica polytechnica

Civil Engineering

$51 / 2(2007) 4750$

doi: 10.3311/pp.ci.2007-2.07

web: http://www.pp.bme.hu/ci

(c) Periodica Polytechnica 2007

TECHNICAL NOTE

\section{Climate change and structural} engineering

\author{
Péter Lenkei
}

Received 2007-11-03

\begin{abstract}
Based on last years experiences it is obvious for the majority of professionals and for the general public too, that climate change is a realistic present and future.

In the beginning this paper deals with the signs and perspectives of climate change. In the second part the consequences of climate change on building and civil engineering structures are treated. The emphasis is laid on the effect of temperature, wind end water circulation of the globe.

The research is directed mainly towards getting reliable future data and its evaluation for practical use.

Finally some aspects of standardization procedure and the problem of old/existing and new structures are treated.
\end{abstract}

\section{Keywords}

climate change $\cdot$ effects on structures $\cdot$ meteorological actions

\section{Acknowledgement}

The author would like to express his sincere gratitude to Professor Judit Bartholy of the Meteorological Chair of L. Eötvös University for her help and understanding.

Acknowledgements are due to the National Office for Research and Technology Development (NKTH) and to the Hungarian Scientific Research Fund (OTKA) for accepting this topic for common future financing.

\section{Péter Lenkei}

Department of Structural Engineering, University of Pécs, H-7625 Boszorkány u. 2, Pécs, Hungary

e-mail: len970@hungarnet.hu
Motto: „Anyone can learn from the past. Today it's a question of learning from the future."

Hermann Kahn

\section{Introduction}

The climate change, the global warming and their consequences are well represented in the media. In addition people experience in everyday life smaller or bigger signs of this process. Nevertheless one can meet skeptic opinions, but the number of such opinions are decreasing due to the obvious evidences.

The problem of climate change is very wide and extremely complex, involving every fields of science, and even every side of the life on the globe.

It should be pointed out, that this problems in structural engineering are important, but involving only a small part of the general problem.

According to the opinion of the author the adaptation and mitigation procedures of the climate change should be applied to the activity of each profession. To draw the consequences, and propose the necessary steps in our profession, in structural engineering is the goal of this paper.

\section{The climate change}

The global warming due to the increased emission of greenhouse gases is investigated by many of the meteorological institutions, offices, bureaus and stations. Great many of reports have been published all around the world.

One of the most important documents is the series of Assessment Reports of the Intergovernmental Panel on Climate Change (established by the UN). The last one titled "Climate Change 2007 - Climate Change Impacts, Adaptation and Vulnerability” (IPCC 2007).

This Report declares „Much more evidence has accumulated over the last five years to indicate the changes in many physical and biological systems linked to anthropogenic warming."

The Report states for the future „Magnitude of impact can now be estimated more systematically for a range of possible increases in global average temperature." 
About the future ,...impact due to the altered frequencies, and intensities of extreme weather, climate and see level events...” the Report pointed out „Disruption by floods and high wind, withdrawal of risk coverage in vulnerable areas by private insurers..." would be of great importance.

Responding to the climate change the Report stressed the necessity of adaptation and mitigation measures.

The above described general situation makes necessary the adaptation and mitigation measures in structural engineering too.

For specifying our task we should know the perspectives on the long term about global warming in the Carpathian Region. In the following some regional aspects, e.g. average temperature increase (Fig. 1) and average precipitation changes (Fig. 2) are shown in the Carpathian Region elaborated by the Meteorology Chair of the Eötvös University, Budapest (Bartholy et al [2]).

In these diagrams are shown the expected change in the period of 2071-2100 relative to 1961-1990 in case of an adverse scenario. The data was drawn from research results of 18 meteorological institution using regional climate change models.

Next years some similar diagrams will be elaborated for average wind speed of the above period by the Meteorology Chair of the L. Eötvös University in the frame of a research project sponsored by the National Office for Research and Technology Development (NKTH) and the Hungarian Scientific Research Fund (OTKA).

3 Possible future impacts of climate change on structures

There are several possible disadvantageous impacts (the following list is not complete).

Impacts of temperature changes

- Drought areas (long seasons without precipitation)

- More frequent freezing-thawing cycles (concrete technology)

- Warming of ocean surfaces (resulting in hurricanes or typhoons)

- Thawing of ice reserves (resulting in rising of see level)

Impacts of precipitation changes

- Bigger and abrupt floods (higher water levels in lakes and rivers)

- Changing of ground water level (foundation problems)

- Heavy abrupt snow falls

- Heavy hails (precipitation in the form of ice lumps)

Impacts of higher wind speed

- Higher wind impulses

- Wind intensity increase is time depended

- Different wind profiles
Impacts of driving rain (combination of heavy rain and large wind speed)

- Deterioration of structural surfaces

- Damage to the water tightness of different elements Impacts of significantly more frequent extremes

- Low cycle fatigue of structural elements

- Accumulation of damages in structures

These drawbacks make absolutely necessary the engineering response. But adaptation and mitigation measures are made difficult by the time dependent (mainly increasing) character of these impacts.

The other problem is the lack of reliable future data base due to uncertain nature of these impacts.

\section{Future research tasks}

One should understand that all the necessary research tasks cannot be solved in the frame of our actually financed four years research and the fact that any research in this field can not made without close cooperation of meteorologists.

4.1 This research can not disregard the temperature and precipitation changes in time

- First of all the temperature changes in time are one of the main bases for every further steps in investigating the effects of climate change

- The yearly frequency of extremes (min and max) and distribution of extremes are in close connection with temperature changes

- The number of freezing and melting cycles are depended on temperature and previous precipitation.

4.2 The main concerns of this research are the problems connected with future wind actions and the future change of the temperature and change of precipitation.

Problems to be solved in the field of wind actions

- The first problem is the traditional wind measuring method. This consists of measuring in each hour or one and half hour the average wind speed in the last ten minutes. Naturally this would not the largest wind speed for the measuring period.

- In addition we need not the average wind speed, but the wind impulse of $3 \mathrm{sec}$ duration. There should be cleared up the relation between the wind speed and wind impulse.

- Another open question is the frequency and distribution of maximal wind speeds.

- The method of interpolation between 1961-1990 and 20712100 average wind speeds should be investigated too.

- Very important question is to determine the relation between the wind profile (the wind speed changes in elevation) and the changing value of the wind speed. 


\section{SPRING (M-A-M)}
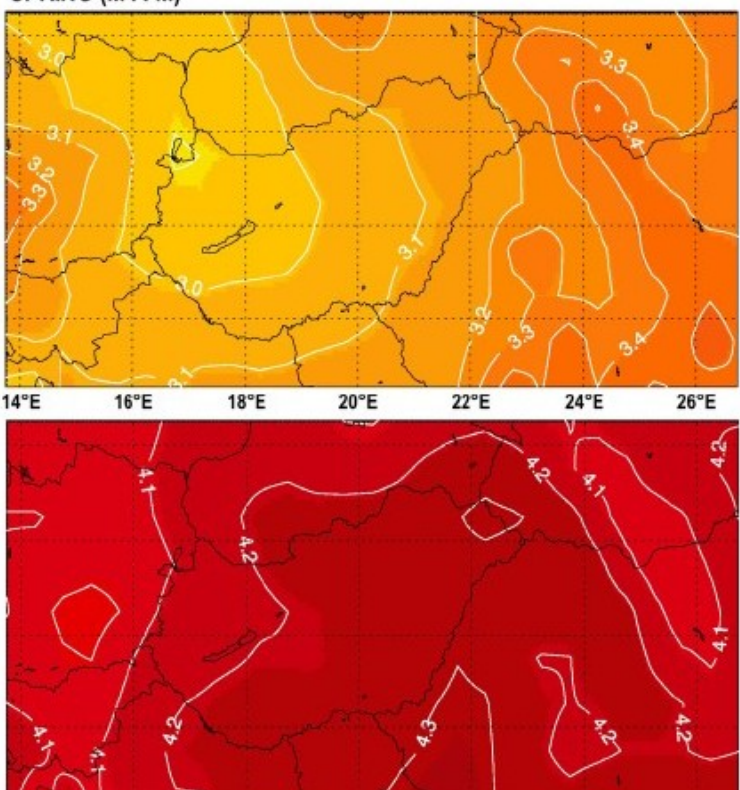

AUTUMN (S-O-N)
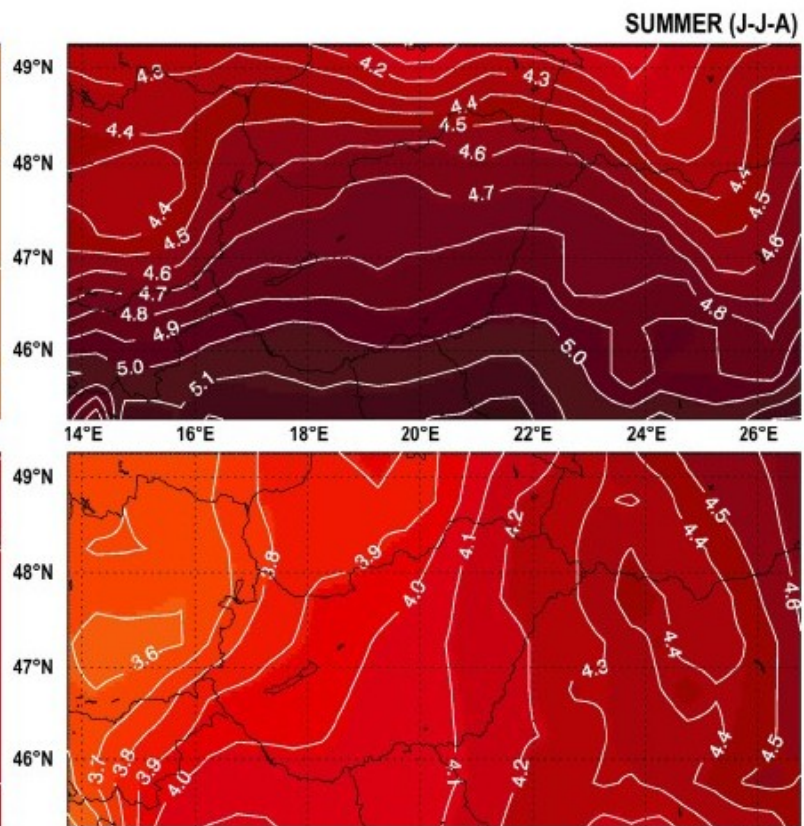

WINTER (D-J-F)

TEMPERATURE CHANGE $\left({ }^{\circ} \mathrm{C}\right)$

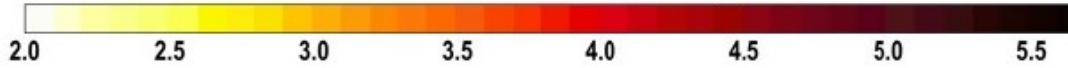

Fig. 1. Seasonal temperature change $\left({ }^{\circ} \mathrm{C}\right)$ in the Carpathian basin for 2071- Dispersion $\sigma=0,3-1,1^{\circ} \mathrm{C}$ 2100 based on European regional model simulation (Bartholy et al.)
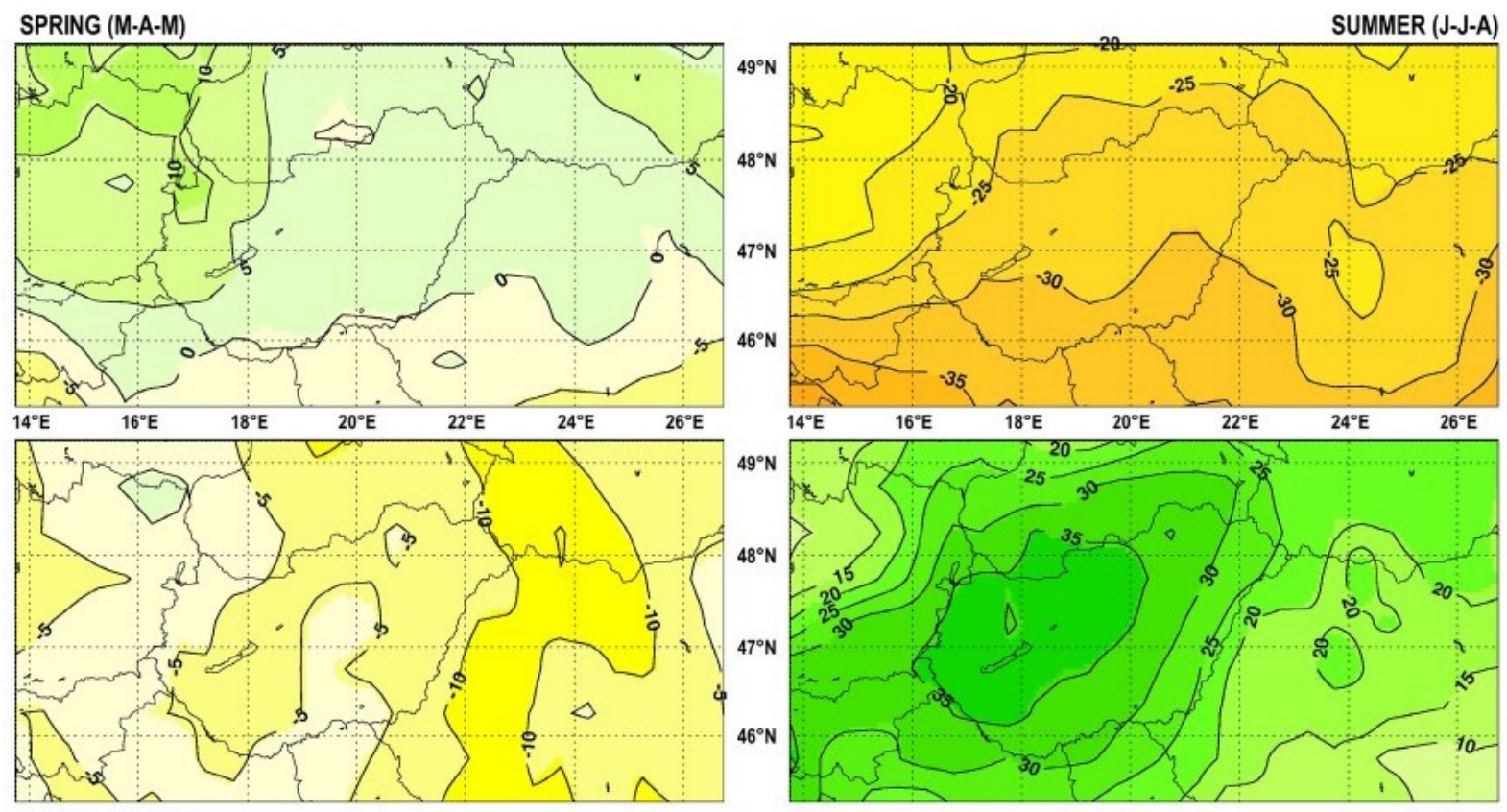

AUTUMN (S-O-N)

PRECIPITATION CHANGE $(\%)$

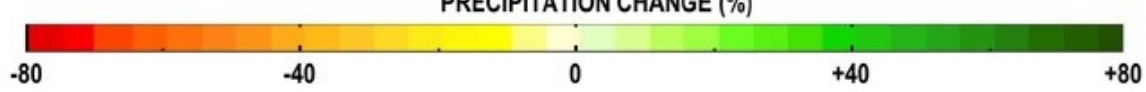

Fig. 2. Seasonal precipitation change (\%) in the Carpathian basin for 2071- Dispersion $\sigma=12-20 \%$ 2100 based on European regional model simulation (Bartholy et al.) 


\section{Standardization of meteorological actions}

The occurrence probability of meteorological actions in different structural design codes generally equal to 0.02 , i.e. 50 years occurrence probability of highest, most dangerous value.

It is obvious, that in changing circumstances the 50 years occurrence probability would be different in each consecutive year.

The other problem is that up to now these values have been determined from relevant past data. In the future these values should be determined from uncertain future data (Lenkei 2006). In addition these uncertain data should be connected functionally with the measured past data and previous uncertain values.

To deal with long term forecast the intervals of revision should be designated. Another solution could be the use of time dependent formulae.

\section{Different design procedure for old/existing and for new structures}

At first sight it appears that the problem of new structures is easy: one just should take into account the new design codes suitable to the challenges of the climate change. They will be a little more expensive, that is all. But do not forget, the today new structures in 10-20 years will be old, the change keep on.

What to do with old/existing structures? Most probable there should be made more or less significant and consequently more or less expensive interventions. These interventions could be different, e.g. change of some structural element(s), strengthening of some part(s) of the structures, change of structural behavior of the whole structure by increasing static indeterminacy or make the structure more robust.

It should be mentioned, that the buildings, the civil engineering and infrastructural objects amounts one of the biggest part of national wealth. Consequently any necessary intervention would be connected with great expenses.

\section{Conclusions}

The structural engineers should take into account among others the obvious climate change and its impacts on structures. The task is not easy: to work out the answers to the challenges of the climate change, namely the adaptation and mitigation measures for old and new structures of buildings and civil engineering objects. Finding the optimal solution(s) would be even more complicated, but this is our task and our responsibility.

\section{References}

1 IPCC Climate Change 2007, Climate Change Impacts, Adaptation and Vulnerability,: Summary for Policymakers, April 6 2007, available at (http: //wWw.ipccc/pub/reports.htm)

2 Bartholy J, Pongrácz R, Gelybó Gy, Regional Climate Change Expected in Hungary for 2071-2100, 2007. Appl.Ecology and Environmental Research 5(1):1-17.

3 Lenkei P, Concrete Structures and the Probable Climate Change: 2nd fib Congress, Doppieroce, Italy, 2006. Condensed Papers (2) 564-565. 